\title{
Toulouse-Lautrec Disease: A Case Report of a Femur Shaft Fracture
}

\author{
Etienne Boyer ${ }^{1}$, Gauthier Menu ${ }^{1}$, Thomas Rondot ${ }^{1}$, Fanny Mille ${ }^{2}$, Maxime Ferrier ${ }^{3}$, Antoine Adam ${ }^{4}$, Laurent Obert $^{1}$, Philippe \\ Liverneaux ${ }^{\text {** }}$
}

${ }^{1}$ Orthopaedic and Traumatology Surgery Service, University Hospital of Besançon, France

${ }^{2}$ Orthopaedic and Traumatology Surgery Service, Hospital of Pontarlier, France

${ }^{3}$ Orthopaedic Surgery Service, Clinical Convert of Bourg en Bresse, France

${ }^{4}$ Orthopaedic and Traumatology Surgery Service, Hospital of Vesoul, France

${ }^{5}$ Department of Hand Surgery, University Hospital of Strasbourg, FMTS, University of Strasbourg, France

"Corresponding author: Philippe Liverneaux, Department of Hand Surgery, SOS main, CCOM, University Hospital of Strasbourg, FMTS, University of Strasbourg, Icube CNRS 7357, 10 Avenue Baumann, 67400 Illkirch, France. Email: Philippe.LIVERNEAUX@ chru-strasbourg.fr

Citation: Boyer E, Menu G, Rondot T, Mille F, Ferrier M, et al. (2018) Toulouse-Lautrec Disease: A Case Report of a Femur Shaft Fracture. J Surg: JSUR-198. DOI: 10.29011/2575-9760. 000098

Received Date: 12 January, 2018; Accepted Date: 06 February, 2018; Published Date: 12 February, 2018

\begin{abstract}
Toulouse-Lautrec disease is a lysosomal autosomal recessive disease responsible of condensing osteopathy and fragility of the bones. The case report featured a 24-year old woman with a right femoral shaft fracture treated by open reduction and plate fixation. Osteosynthesis by nail was not possible because the femur medullar tunnel was obstructed. Before surgery, the surgeon must be aware of the potential obstruction of the femoral medullar tunnel in this type of patient.
\end{abstract}

Keywords: Condensing Osteopathy; Femoral Shaft Fracture; Pycnodysostosis; Toulouse-Lautrec Disease

\section{Introduction}

The first case of pycnodysostosis was described by Montanari in 1962 [1] and then named in 1965 Toulouse-Lautrec disease after it was found out the famous 19th century painter had it $[2,3]$. The prevalence of pycnodysostosis is unknow in the literature. We report a case of pycnodysostosis with a femur diaphysis shaft treated by open reduction and plate fixation. This method was chosen as a result of the characteristics of the disease forcing to avoid nail fixation.

\section{Case Report}

A 24-year old woman was referred to our hospital with a right femoral shaft fracture which occurred as she got out of her car. She had already been diagnosed with pycnodysostosis as a young child. No history of pycnodysostosis or consanguinity had previously been noted in her family. The physical examination highlighted a distinctive dysmorphic syndrome with a stature deficiency $(141 \mathrm{~cm}, 43 \mathrm{~kg})$, a bradymetacarpia with short and brittle nails (Figure 1A), facial dimorphic disorder showing a small face with prominent frontal lump, a protruding nose, a large forehead and a micrognathia. The mouth analysis displayed dental issues. No abdominal organomegaly was found and the blood tests were standard, especially phospho-calcic balance. Hands and feet Xrays showed an acro-osteolysis and an aplasia of the last phalanxes of the fingers and toes (Figure 1B). The cranium radiography emphasized the anterior fontanel and the presence of abnormally large stitches (Figure 1C). The remainder radiographs of the peripheral skeleton underlined asymptomatic fractures at the base of the first phalanxes on the first and second toes, at the base of the fourth and fifth left foot metatarsal, and an anterior unicortical fracture of the left tibial diaphysis which had been treated a few months earlier conservatively (Figure 1D \& 1E). All these lesions occurred as a result of low energy trauma. 


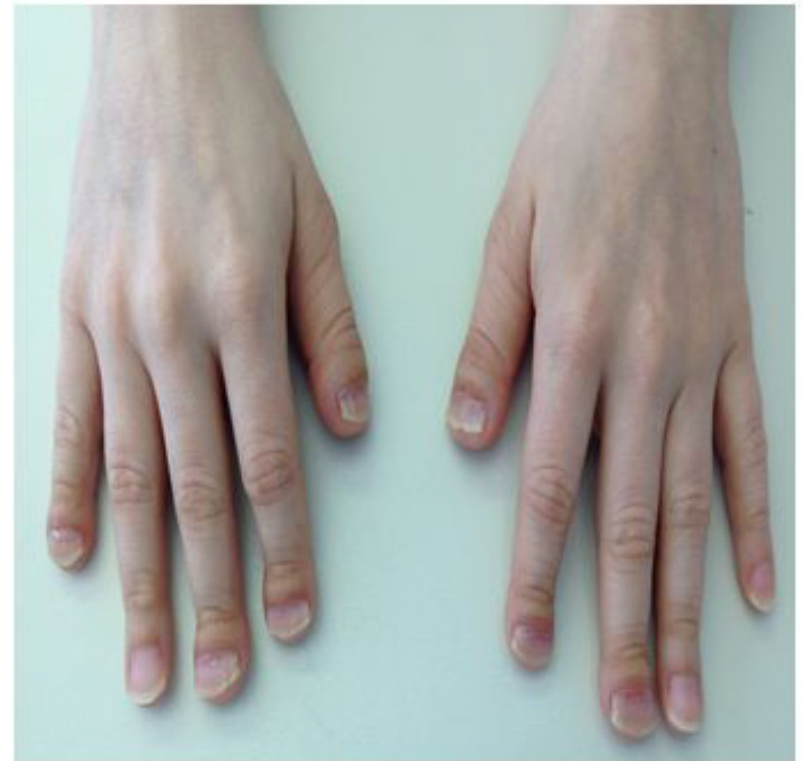

A

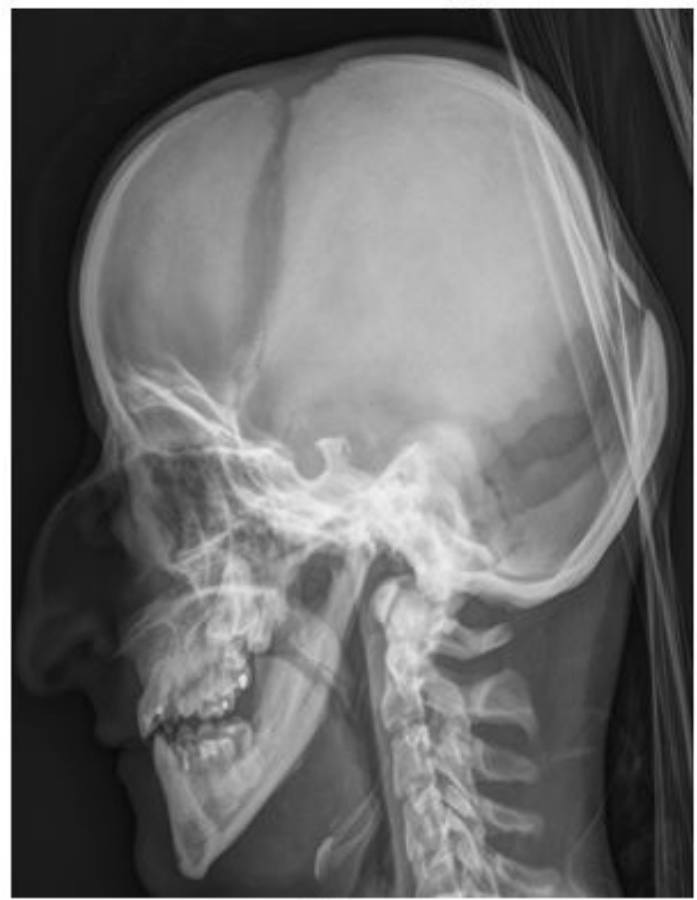

C

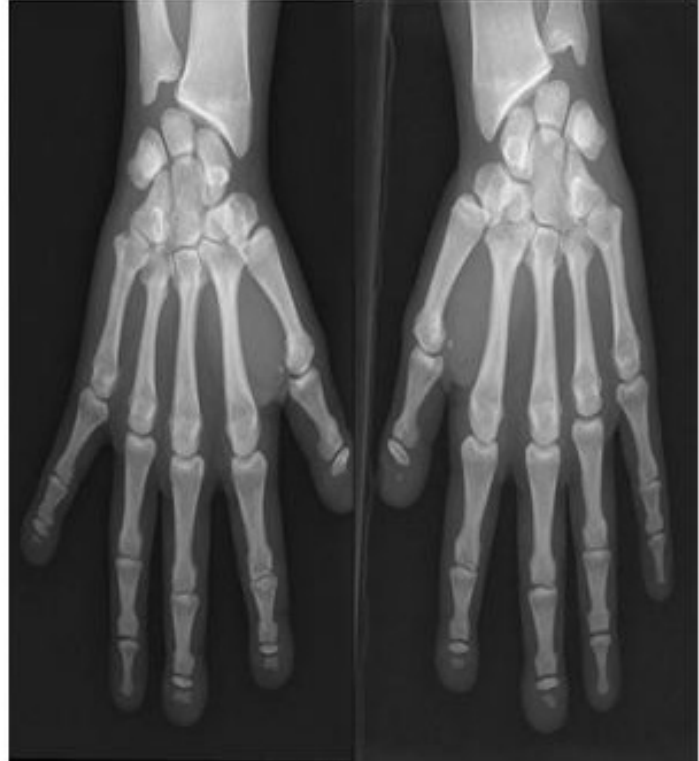

B

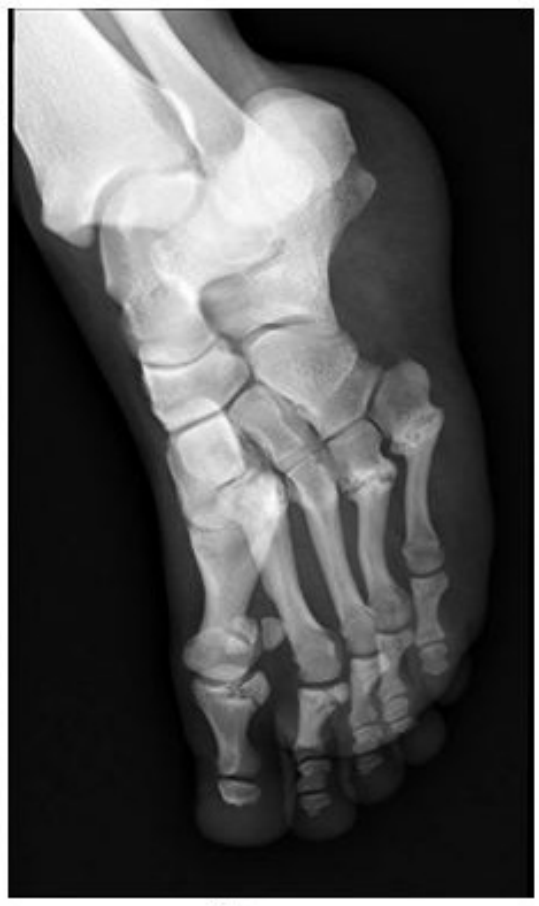

D

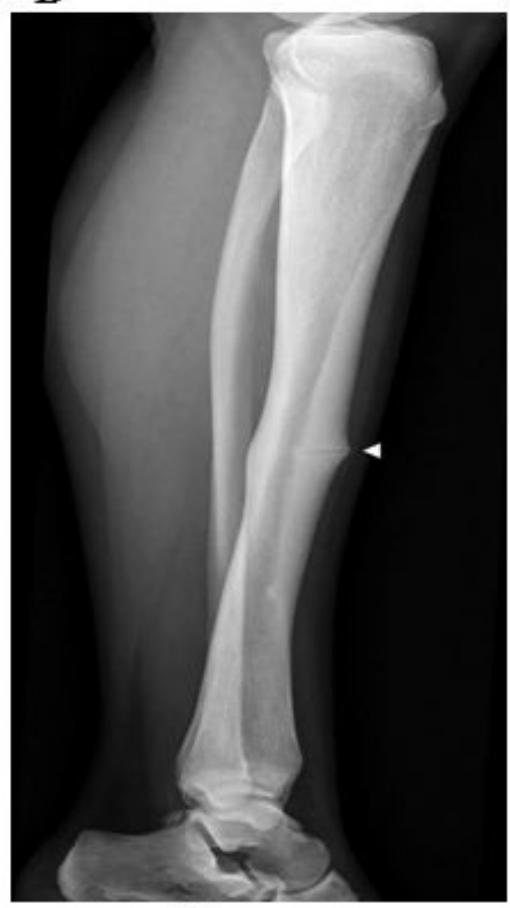

E

Figures 1(A-E): Toulouse-Lautrec disease: a case: A) Bradymetacarpia with short and brittle nails; B) Hands X-ray showing an acro-osteolysis and an aplasia of the last phalanxes of the fingers; C) Cranium X-ray showing an osteocondensation of the base of the skull, Hypoplasia of the bones and the lower jaw, with disappearance of the mandibular angle; D) Left foot x-ray showing fractures at the base of the first phalanxes on the first and second toes, at the base of the fourth and fifth left foot metatarsal. E) Left leg x-ray showing an anterior unicortical fracture of the left tibial diaphysis (white arrow).

It was decided that the right femur shaft fracture would be treated by surgery (Figure 2A). The patient was laid on the surgery table in a left lateral decubitus position after general anaesthesia associated with a locoregional anaesthesia achieved by femoral nerve block. The lateral approach of the thigh enabled access to the centre of the fracture (Figure 2B). After reduction using Verbrugge pliers, it was 
decided to proceed to an osteosynthesis with 10 holes $4,5 \mathrm{~mm}$ long LCP plate (Depuy Synthes ${ }^{\mathrm{TM}}$ ). Three locked screws were placed above the centre of the fracture and another three were positioned under the centre. During surgery, it was observed that the femur medullar cavities were obstructed which would have prevented an osteosynthesis using an intramedullary nail. The cavities have been made permeable again by drilling through them in order to increase the intake of bone growth factors (Figure 2C). A bone density unusually high made difficult the drilling and screwing of the femoral corticalis.

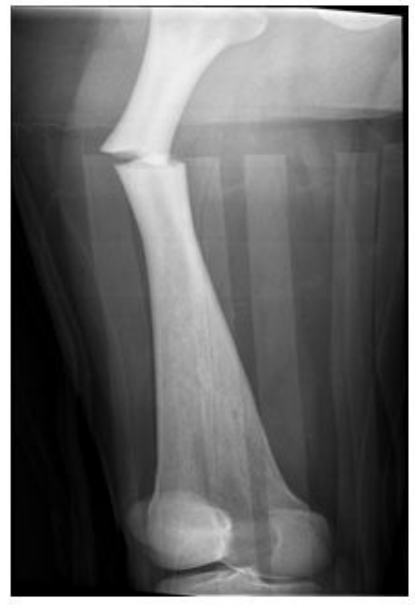

A

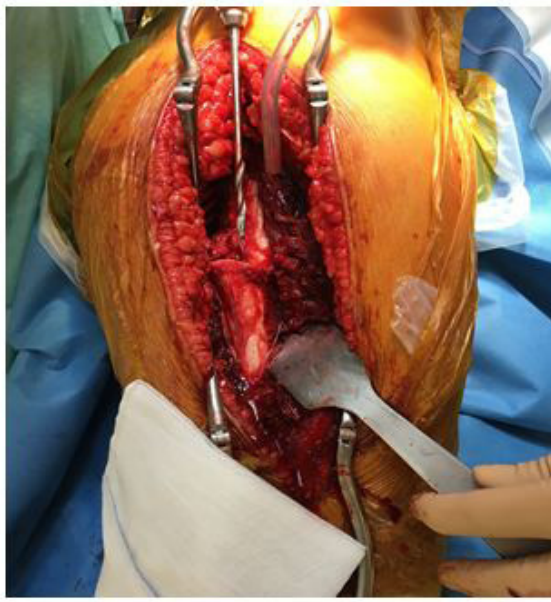

B

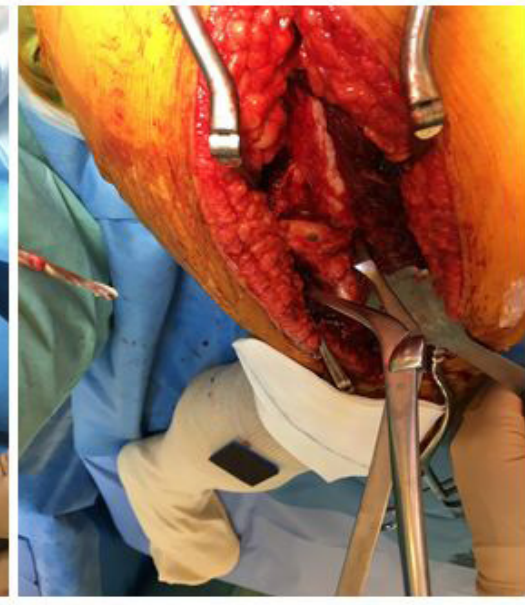

C

Figures 2(A-C): Preoperative view of a right femur fracture in a case of Toulouse-Lautrec disease. A) X-ray showing a shaft fracture of right femur; B) Lateral approach of the thigh enabled access to the center of the fracture. The operator was about to permeabilize the medullary tunnel with the drill; C) Appearance of the femoral shaft after drilling.

Post-surgery, weight-bearing was prohibited for a three months period. The day following surgery, rehabilitation, by strengthening of the quadriceps muscle, begun along with support of the articular range on the limb which underwent surgery, and the learning of how to walk using crutches. The immediate post-surgery consequences did not show any complications such as cutaneous healing or hematoma issues. The progression was effective and allowed the patient to stand at three months with no associated pain or physical aid. The femur X-rays taken during the follow-up eventually showed a bone callus on the third month (Figure 3). This finding confirmed the existence of a slow bone healing with this type of patient.

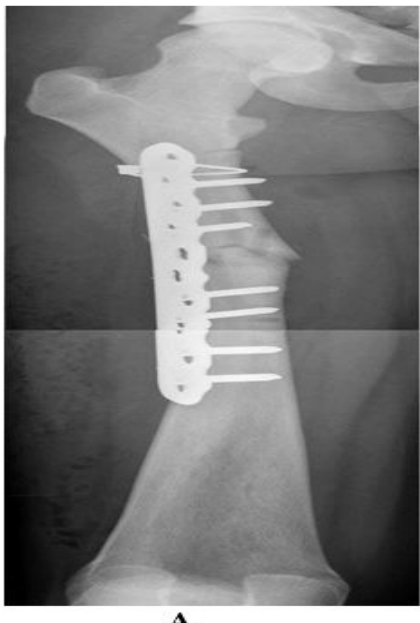

A

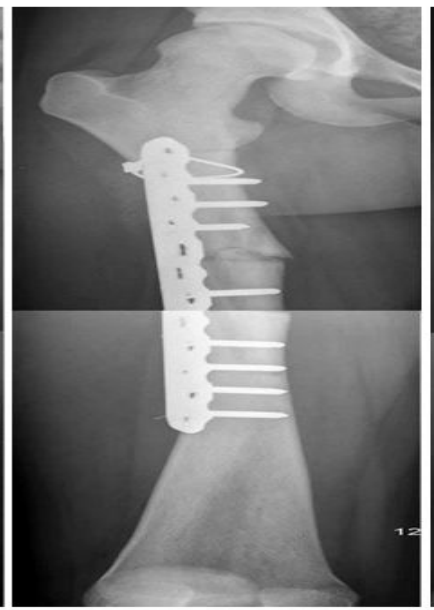

B

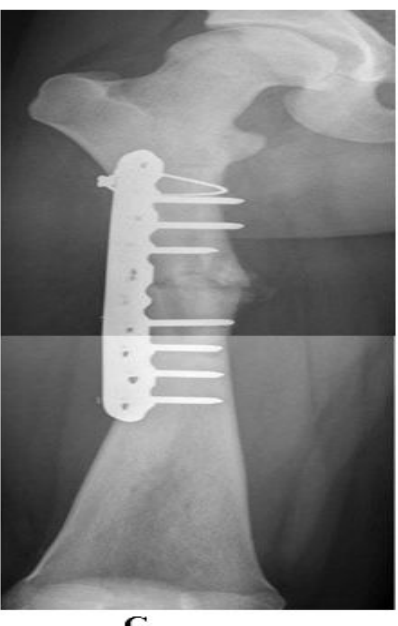

$\mathbf{C}$

Figure 3: Radiographic postoperative result of a right femur fracture treated by plate fixation. A) after 1 week; B) after 1 month; C) after 3 months. 


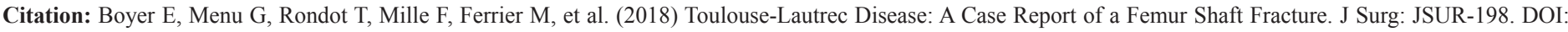
10.29011/2575-9760. 000098

\section{Discussion}

The pycnodysostosis (from Greek, pycnos = dense, dys $=$ faulty, osteon = bone) is a seldom bone dysplasia at the root of the increase in density and fragility of the bones leading to repetitive shock less fractures impacting mainly the lower limbs and especially the femur. It is a lysosomal autosomal recessive disease responsible of condensing osteopathy. The anomaly is located on the 1 -chromosome in $1 \mathrm{q} 21$ which codes for cathepsin $\mathrm{K}[4,5]$. It is a lysosomal protease secreted by the osteoclast enabling the proteins breakdown from the bone matrix such as Type I collagen, osteonectin, or osteopontin. The pycnodysostosis results from mutation of this gene and is characterised by bones that are highly dense but also fragile due to bone restructuration related problems [6-9].

Generally, this disease is diagnosed during childhood where a small body height clashes with a relatively large skull, a lack of closure on the anterior fontanels and a facial dysmorphism. The illness can sometime be spotted during the adult age either after a fracture or during a punctual check-up. From a clinical perspective, the patients display distinctive cranial malformations with a large skull associated with the presence of wormian bones, a persistence of the anterior fontanel and a mandibular hypoplasia. The thorax is narrow with a collarbone dysplasia. Small and square hands and feet feature short fingers and toes resulting from an acro-osteolysis and an aplasia of the last phalanxes. Dental and ungueal issues can also be observed as well as a bone fragility, which causes fractures. These fractures occur after impacts happening at low-energy, in a repetitive manner, and essentially affecting the lower limbs [10,11]. The exact pycnodysostosis prevalence remains unknown but is estimated to range within 1 and 1.7 over a million childbirths with an even distribution across both sexes [12]. As per any recessive autosomic transmissible diseases, consanguinity increases the risk of appearance. It arises in $30 \%$ of the cases.

No specific treatment against pycnodysostosis is currently available [13]. The use of growth hormones produces encouraging results on the development [14]. The genetic therapy is still at the experimental stage similarly to the substitutive enzymotherapy and the cathepsin $\mathrm{K}$ inhibitors used in the treatment against osteoporosis [15-17]. Most of the treatment primarily bears a preventive aim with an early screening and a regular monitoring of the fractures, which strengthening is often slowed down. The screening test in the pre-birth diagnosis is not done systematically, but is considered for the couples that have already had a child affected by the disease [18-23]. In our cas, the obstruction of the medullar tunnel has been noticed while surgery was in progress. This physical anomaly has a crucial impact upon the choice of the fixing system that will be used during the osteosynthesis. Several authors have mentioned about the technical difficulties related to the osteosynthesis via intramedullary nail with locking pin. Some even prefer using a plate in the event of a contralateral femur osteosynthesis [19].
Regardless of the risk of surgical site infection and the loss of the fracture hematoma, a plate fixation yet appeared as an astute choice given the anatomical particularity. This therapeutic alternative is also proposed by Azagui, et al. [20].

Overall, the pycnodysostosis is a seldom cause of condensing osteopathy often diagnosed during childhood, responsible of a typical dysmorphic syndrome associated with an increased bone fragility. It belongs to the genotypic osteopathy group. No curative treatment for this affection currently exists. The approach therefore lies on the complications presented by the patient and particularly any fractures of the peripheral bones such as the case of this report. While proceeding to the pre-surgery exercise, the surgeon must be aware of the potential obstruction of the femoral medullar tunnel.

\section{References}

1. Elmore SM (1967) Pycnodysostosis: A Review. J Bone Jt Surg Am 49: 153-162.

2. Maroteaux P and Lamy M (1965) The Malady of Toulouse-Lautrec. JAMA 191: 715-717.

3. Hodder A, Huntley C, Aronson JK, Ramachandran M (2015) Pycnodysostosis and the making of an artist. Gene 555: 59-62.

4. Gelb BD, Edelson JG, Desnick RJ (1995) Linkage of pycnodysostosis to chromosome 1q21 by homozygosity mapping. Nat Genet 10: 235-237.

5. Polymeropoulos MH, Ortiz De, Luna RI, Ide SE, Torres R, et al. (1995) The gene for pycnodysostosis maps to human chromosome 1cenq21. Nat Genet 10: 238-239.

6. Motyckova G and Fisher DE (2002) Pycnodysostosis: role and regulation of cathepsin $\mathrm{K}$ in osteoclast function and human disease. Curr Mol Med 2: 407-421.

7. Gelb BD, Moissoglu K, Zhang J, Martignetti JA, Brömme D, et al (1996) isolation and characterization of the murine cDNA and genomic sequence, the homologue of the human pycnodysostosis gene. Biochem Mol Med 59: 200-206.

8. Xue Y, Cai T, Shi S, Wang W, Zhang Y, et al. (2011) Clinical and animal research findings in pycnodysostosis and gene mutations of cathepsin K from 1996 to 2011. Orphanet J Rare Dis 6: 20.

9. Fujita Y, Nakata K, Yasui N, Matsui Y, Kataoka E, et al. (2000) Novel mutations of the cathepsin $\mathrm{K}$ gene in patients with pycnodysostosis and their characterization. J Clin Endocrinol Metab 85: 425-431.

10. Mujawar Q, Naganoor R, Patil H, Thobbi AN, Ukkali S, et al. (2009) Pycnodysostosis with unusual findings: a case report. Cases J 2: 6544.

11. Karakurt L, Yilmaz E, Belhan O, Serin E (2003) Pycnodysostosis associated with bilateral congenital pseudarthrosis of the clavicle. Arch Orthop Trauma Surg 123: 125-127.

12. Turan S (2014) Current research on pycnodysostosis. Intractable Rare Dis Res 3: 91-93.

13. Alves Pereira D, Berini Aytés L, Gay Escoda C (2008) Pycnodysostosis. A report of 3 clinical cases. Med Oral Patol Oral Cirugia Bucal 13: $633-635$. 
Citation: Boyer E, Menu G, Rondot T, Mille F, Ferrier M, et al. (2018) Toulouse-Lautrec Disease: A Case Report of a Femur Shaft Fracture. J Surg: JSUR-198. DOI: 10.29011/2575-9760. 000098

14. Rothenbühler A, Piquard C, Gueorguieva I, Lahlou N, Linglart A, et al. (2010) Near normalization of adult height and body proportions by growth hormone in pycnodysostosis. J Clin Endocrinol Metab 95: 2827-2831.

15. Harmatz P, Kramer WG, Hopwood JJ, Simon J, Butensky E, et al. (2005) Mucopolysaccharidosis VI Study Group. Pharmacokinetic profile of recombinant human $\mathrm{N}$-acetylgalactosamine 4-sulphatase enzyme replacement therapy in patients with mucopolysaccharidosis $\mathrm{VI}$ (Maroteaux-Lamy syndrome): a phase I/II study. Acta Paediatr Suppl 94: 61-68.

16. Yates CJ, Bartlett MJ, Ebeling PR (2011) An atypical subtrochanteric femoral fracture from pycnodysostosis: a lesson from nature. J Bone Miner Res Off J Am Soc Bone Miner Res 26: 1377-1379.

17. Duong LT, Leung AT, Langdahl B (2016) Cathepsin K Inhibition: A New Mechanism for the Treatment of Osteoporosis. Calcif Tissue Int 98: 381-397.

18. Azagui Y, Zaidane A, Belmoubarek A, Ahed K, Haddoun A, et al. (2013) Diaphyseal femur fracture in pycnodysostosis: a case report. Rev Mar Rhum 24: 52-55.
19. Hashem J, Krochak R, Culbertson MD, Mileto C, Goodman H (2015) Atypical femur fractures in a patient with pycnodysostosis: a case report. Osteoporos Int J Establ Result Coop Eur Found Osteoporos Natl Osteoporos Found USA 26: 2209-2212.

20. Kundu ZS, Marya KM, Devgan A, Yadav V, Rohilla S (2004) Subtrochanteric fracture managed by intramedullary nail in a patient with pycnodysostosis. Joint Bone Spine 71: 154-156.

21. Bor N, Rubin G, Rozen N (2011) Fracture management in pycnodysostosis: 27 years of follow-up. J Pediatr Orthop Part B 20: 97-101.

22. Roth VG (1976) Pycnodysostosis presenting with bilateral subtrochanteric fractures: case report. Clin Orthop 117: 247-253.

23. Nakase T, Yasui N, Hiroshima K, Ohzono K, Higuchi C, et al. (2007) Surgical outcomes after treatment of fractures in femur and tibia in pycnodysostosis. Arch Orthop Trauma Surg 127: 161-165. 